\title{
Modified Regression Rate Formula of PMMA Combustion by a Single Plane Impinging Jet
}

\author{
Tsuneyoshi Matsuoka, ${ }^{1}$ Kyohei Kamei, ${ }^{1}$ Yuji Nakamura, ${ }^{1}$ and Harunori Nagata ${ }^{2}$ \\ ${ }^{1}$ Department of Mechanical Engineering, Toyohashi University of Technology, Toyohashi, Japan \\ ${ }^{2}$ Division of Mechanical and Space Engineering, Hokkaido University, Sapporo, Japan \\ Correspondence should be addressed to Tsuneyoshi Matsuoka; matsuoka@me.tut.ac.jp
}

Received 26 September 2016; Accepted 18 January 2017; Published 21 February 2017

Academic Editor: Corin Segal

Copyright (c) 2017 Tsuneyoshi Matsuoka et al. This is an open access article distributed under the Creative Commons Attribution License, which permits unrestricted use, distribution, and reproduction in any medium, provided the original work is properly cited.

A modified regression rate formula for the uppermost stage of CAMUI-type hybrid rocket motor is proposed in this study. Assuming a quasi-steady, one-dimensional, an energy balance against a control volume near the fuel surface is considered. Accordingly, the regression rate formula which can calculate the local regression rate by the quenching distance between the flame and the regression surface is derived. An experimental setup which simulates the combustion phenomenon involved in the uppermost stage of a CAMUI-type hybrid rocket motor was constructed and the burning tests with various flow velocities and impinging distances were performed. A PMMA slab of $20 \mathrm{~mm}$ height, $60 \mathrm{~mm}$ width, and $20 \mathrm{~mm}$ thickness was chosen as a sample specimen and pure oxygen and $\mathrm{O}_{2} / \mathrm{N}_{2}$ mixture (50/50 vol.\%) were employed as the oxidizers. The time-averaged regression rate along the fuel surface was measured by a laser displacement sensor. The quenching distance during the combustion event was also identified from the observation. The comparison between the purely experimental and calculated values showed good agreement, although a large systematic error was expected due to the difficulty in accurately identifying the quenching distance.

\section{Introduction}

1.1. Design of Fuel Grain for CAMUI-Type Hybrid Rocket Motor. A conventional hybrid rocket, which typically uses a solid as fuel with a liquid or gas as oxidizer, has several disadvantages and the critical issue among those is the low regression rate $[1,2]$. In the hybrid rocket, the combustion of oxidizer gas and pyrolyzed vapor from the fuel grain takes place in the boundary layer and the diffusion flame is established. The mixing and combustion process results in slightly lower overall combustion efficiency and eventually causes a lower regression rate. In fact, the regression rate of HTPB, which is a conventional fuel, is typically an order of magnitude lower than solid propellants. To overcome this disadvantage and enhance the fuel regression rate, several ideas have been proposed: ideas based on the grain shape and/or the injector [3-6] and employing novel fuels [7-10].

The Cascaded Multistage Impinging-jet type hybrid rocket (so-called "CAMUI" hybrid rocket) developed in Hokkaido University is also one of new types of hybrid rockets [11]. The concept is based on a unique configuration of the fuel grain which allows the regression rate to be enhanced without changing fuel materials or injectors. The fuel grain consists of multiple combustible blocks having two ports and they are shifted by 90 degrees each in an axial arrangement. The oxidizer and/or burnt gas flow through the ports and repeatedly impinge to the next fuel block. The regression with and without combustion take place at the front-end and back-end surfaces of the fuel block by the impinging jet as well as the inner port surfaces. The impinging jet and the multiple burning surfaces accelerate the regression; thus they can improve thrust density at least three times larger than a conventional hybrid rocket [11]. Recently, the group has developed $15 \mathrm{kN}$ thrust level CAMUI-type hybrid rocket and successfully performed a static firing test in 2014 [12].

A key parameter for the design of a hybrid rocket motor is the regression rate. Marxman and Gilbert developed a wellknown theory which provides the basic understanding of the regression behavior of hybrid rocket combustion $[13,14]$. Their model is based on combustion over a flat fuel surface in 
a turbulent boundary layer and the regression rate is governed by convective heat transfer from the flame to the fuel surface. Considering the convective heat transfer as well, the following regression rate formula for each burning surface of CAMUItype motor, that is, the upstream end face, downstream end face, and port inner wall, has been developed [15-17]:

$$
\dot{r}=c\left(G_{p}\right)^{m}\left(\frac{H}{D}\right)^{n},
$$

where $G_{p}\left[\mathrm{~kg} / \mathrm{m}^{2} \cdot \mathrm{s}\right]$ is the mass flux of propellant, $H[\mathrm{~mm}]$ is separation distance between the fuel blocks, and $D[\mathrm{~mm}]$ is the port diameter. $c, m$, and $n$ are empirical constants which vary depending on the local $\mathrm{O} / \mathrm{F}$ ratio. Since the propellant mass flux is a function of not only the oxygen mass introduced but also the evaporated fuel mass, the propellant mass flux varies along the flow. Thus, the regression behavior of the uppermost stage is critically important. In other words, the regression rate of the uppermost stage may change the overall performance of CAMUI hybrid rocket motor.

1.2. Regression Rate Formula for Uppermost Stage. It is noticed that the above regression rate formula (i.e., (1)) predicts well except for the front-end surface of the uppermost fuel [16, 17]. According to Nagata et al. [17], it is because the pure oxygen gas impinges to the fuel surface in the uppermost stage, while the high temperature burnt gas is considered as working fluid in the following stages. The gasified oxygen reacts with the gaseous fuel and the flame establishes very close to the fuel surface there; the conduction is a rather dominant heat transfer. Therefore, the regression rate formula based on the convective heat transfer from the burnt gas may not be applied in the existence of the flame.

In addition to its applicability, several ambiguities remain in the conventional regression rate formula. The first one is that the formula requires empirical constants. In order to determine the values, preliminary tests must be carried out before starting the development of new motors which, in turn, creates high cost. In engineering point of view, to minimize the fuel residue is another important issue because it potentially blocks the nozzle and results in serious accidents such as explosion. However, it is impossible to predict the "local" regression rate by the conventional regression rate formula which provides only the spatial averaging regression rate over the whole combustion surface. To overcome these issues, the regression rate formula which can predict the local regression rate without any empirical constants and is applicable to the uppermost stage is needed for optimal design of CAMUI hybrid rocket motor.

The aim of this study is to develop a modified regression rate formula and validate it experimentally. First, burning tests of PMMA with a planar impinging oxidizer jet are performed and the local regression rate along the fuel surface is investigated for various impinging flow velocities and impinging distance. Although the experimental system is different from the actual CAMUI-type hybrid rocket motor, it is expected to reproduce the fundamental physics of the regression behavior of the uppermost stage. The modified regression rate formula which allows the calculation of the

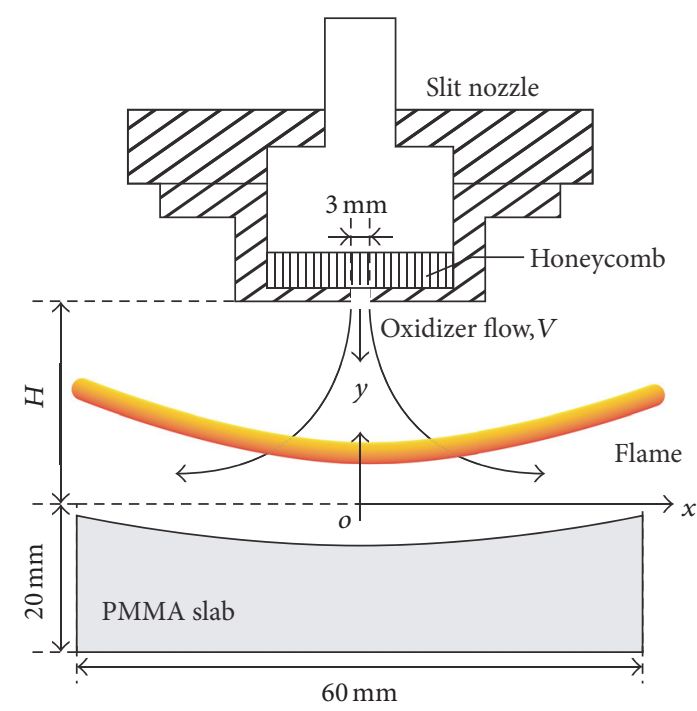

FIGURE 1: Schematic image of experimental apparatus.

local regression rate with only the quenching distance is then derived considering a one-dimensional energy balance for a control volume near the fuel surface. The regression rate calculated is compared with the measurement data for validation.

\section{Experimental Methods}

A schematic image of the experimental model is shown in Figure 1. A PMMA was used as a fuel and its height, width, and depth were $20 \mathrm{~mm}, 60 \mathrm{~mm}$, and $20 \mathrm{~mm}$, respectively. The sample specimen of fuel was held by a stainless holder and installed below the nozzle. An oxidizer gas was ejected through a slit nozzle (width $3 \mathrm{~mm}$ and depth $30 \mathrm{~mm}$ ) and a planer jet impinged to the sample. The location of sample specimen and the impinging distance, $H[\mathrm{~mm}]$, between the sample and the nozzle exit were adjusted by a traverser. The oxidizer gas was supplied through the nozzle. The flow velocity and the oxygen concentration were adjusted by a gas flow control system. In this study, the pure oxygen or $\mathrm{O}_{2} / \mathrm{N}_{2}$ mixture gas containing 50 vol.\% oxygen was used as an oxidizer. The oxygen concentration of the mixture gas was preliminary confirmed by the gas chromatography. The flow velocity at the nozzle exit, $V[\mathrm{~m} / \mathrm{s}]$, was set in the range of 1.9 to $11 \mathrm{~m} / \mathrm{s}$. A honeycomb that is $10 \mathrm{~mm}$ thick, having 100 cells per $100 \mathrm{~cm}^{2}$, is built in the nozzle to rectify the oxidizer flow, although measurement of the velocity profile of the ejecting jet is not attempted in this study. Instead, the mean flow velocity was calculated from calibrated volume flow rates by means of the continuity equation. According to the test condition of oxygen concentration and flow velocity, several volume flow meters (variable-area flow meters) were used. For the pure oxygen test, we used three different flow meters properly (all of them were MODEL RK1200 SERIES available from KOFLOC). In addition to them, the MODEL RK1700 SERIES was used for 50 vol.\% oxygen test. The MODEL RK1200 SERIES has the precision accuracy of less than $2 \%$ 

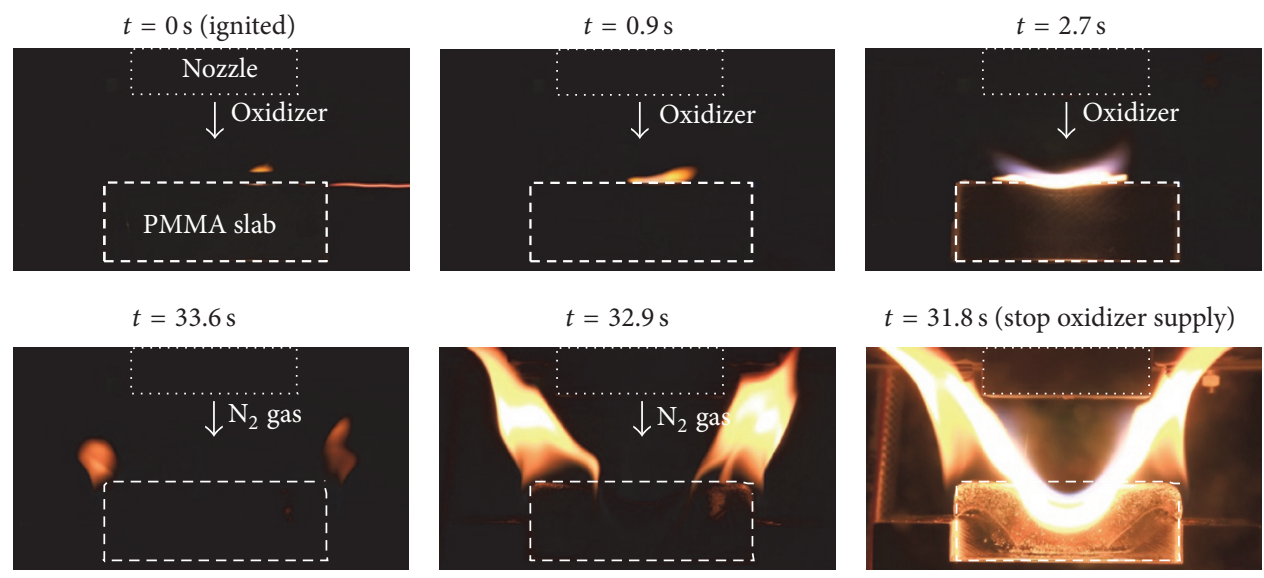
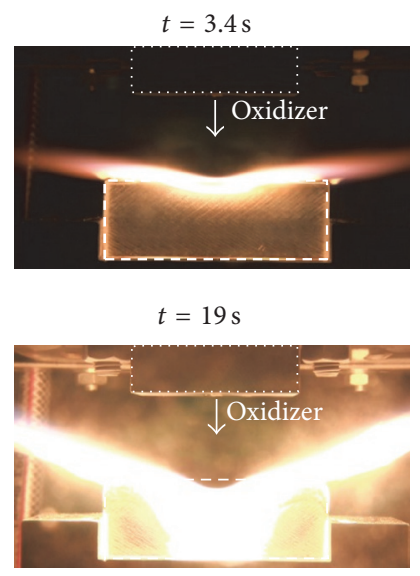

FIgURE 2: Time sequential images of PMMA combustion for $V=5.6 \mathrm{~m} / \mathrm{s}$ and $H=24 \mathrm{~mm}$.

FS, while that of RK1700 is less than $7 \%$ of FS. The volume flow rate was preliminarily calibrated. The calibration tests were performed as follows. The volume flow rate was set to a certain value and the actual flow rate was measured using a dry gas meter. Then, the set value was varied in a range of each flow meter. The test at the certain flow rate was repeated 12 times. The averaged data was plotted against the setting value and then fitted to a line by using the square least method. The calibration tests were done for all the flow meters used. The corresponding Reynolds number $(\mathrm{Re})$ based on the slit width was between about 340 and 2100. It is noted that the experiments were conducted for much lower Re than the actual CAMUI-type hybrid rocket motor to validate the modified regression rate under the existence of the flame avoiding extinguishment.

Ignition to the sample specimen was introduced by an electric wire after confirming the obtained constant flow rate. Followed by successful ignition, the igniter was quickly removed. The combustion was forcibly stopped by introducing nitrogen gas. The entire combustion event was recorded by digital video camera (iVIS HF G20, CANON) or CCD camera (XC-EU50, SONY). The elapsed time until the flame experiences extinction, $t[\mathrm{~s}]$, was obtained from the recorded movie.

After the combustion test, the regression depth along the horizontal axis, $r(x)[\mathrm{mm}]$, defined as a distance from unburnt (initial) surface to burnt surface of the sample, was measured by a laser displacement sensor. The laser displacement was calibrated to output $\pm 5 \mathrm{~V}$ when detecting $\pm 20 \mathrm{~mm}$. The burnt sample was fixed on a linear slider and the regression data was acquired. The sample edge has a large influence on the combustion phenomenon and the phenomenon cannot be assumed as two-dimensional. In order to eliminate the edge effect, all the measurement points were located at the center of depth direction in the range of $-20<x<20 \mathrm{~mm}$. As discussed later, assuming the regression phenomenon is steady, the time-averaged local regression rate, $\dot{r}(x)$, was determined as the regression amount per unit of the elapsed time, $\dot{r}(x)=r(x) / t$.

\section{Results and Discussion}

3.1. Measurement of Regression Rate. Figure 2 shows time sequential images of PMMA burning for $V=5.6 \mathrm{~m} / \mathrm{s}$. A reference time, $t=0$, is set to the time at which the ignition is successfully confirmed. The flame spreads in the horizontal direction for the first few seconds, and then the flame covered the entire region above the fuel. The flame was extinguished at a certain time by introducing nitrogen gas through the nozzle. The elapsed time until the flame experiences extinction, $t[\mathrm{~s}]$, was derived from the obtained movie. Figure 3(a) shows the regression amount from the initial unburnt surface plotted against the elapsed time at the representative locations. The regression amount linearly increases, suggesting that steady combustion is successfully achieved except for the initial 10 seconds after the ignition. Hence, the time-averaged regression rate, defined as the regression amount divided by the elapsed time, was evaluated as shown in Figure 3(b). The regression rate increases as the test proceeds during the initial duration. Later, a nearly constant regression rate was obtained within the entire region of the fuel. Accordingly, the elapsed time was set to about $30 \mathrm{~s}$ to eliminate the ignition disturbance on the regression rate in the following experiments. Kaneko et al. measured the regression rate of polyethylene of which thermal diffusivity is larger than that of PMMA by ultrasonic pulse-echo technique and obtained the steady regression rate within $100 \mathrm{~s}$ before the extinction treatment [15]. Thus, the time-averaged regression rate used in this study is considered as an adequate parameter for the evaluation. Since the experiment was performed only once, it is impossible to evaluate the uncertainty for these experiments. However, it may be deduced to the same extent as those obtained for 50 vol.\% oxygen test (see Figure 7).

Figure 4 shows the local regression rate along the horizontal axis for the impinging distance equal to $24 \mathrm{~mm}$. Note that the local regression rate seems symmetric to the center axis $(x=0)$, and the figure shows averaged regression rates on both $|x|>0$ sides. The maximum regression rate is obtained in the vicinity of the center and it gradually decreases outwardly. For the solid combustion 


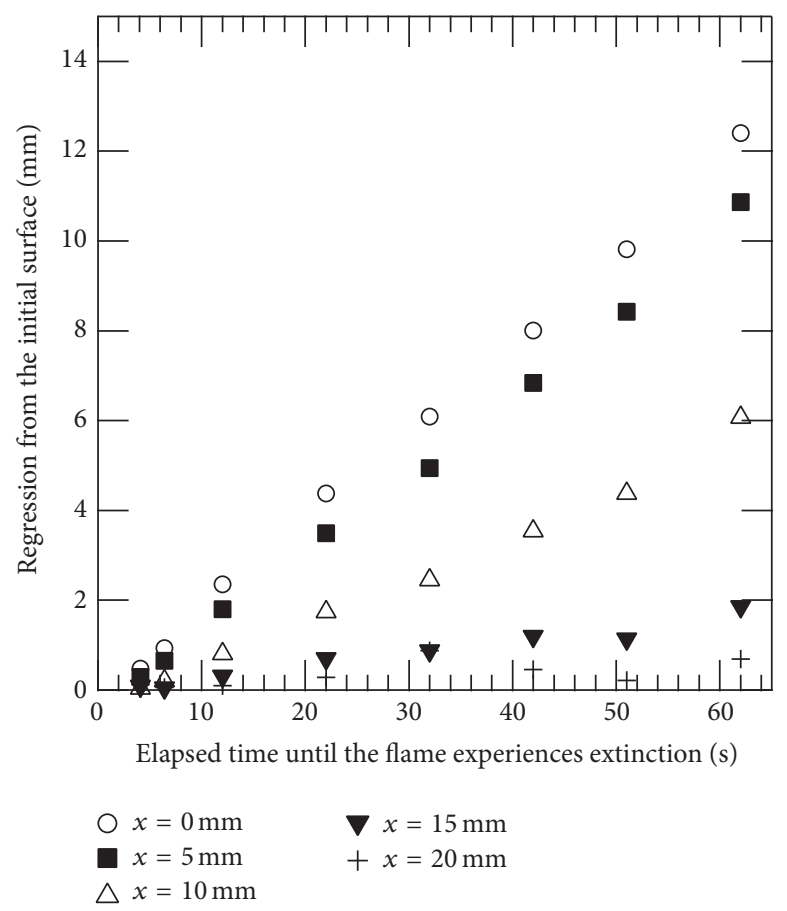

(a)

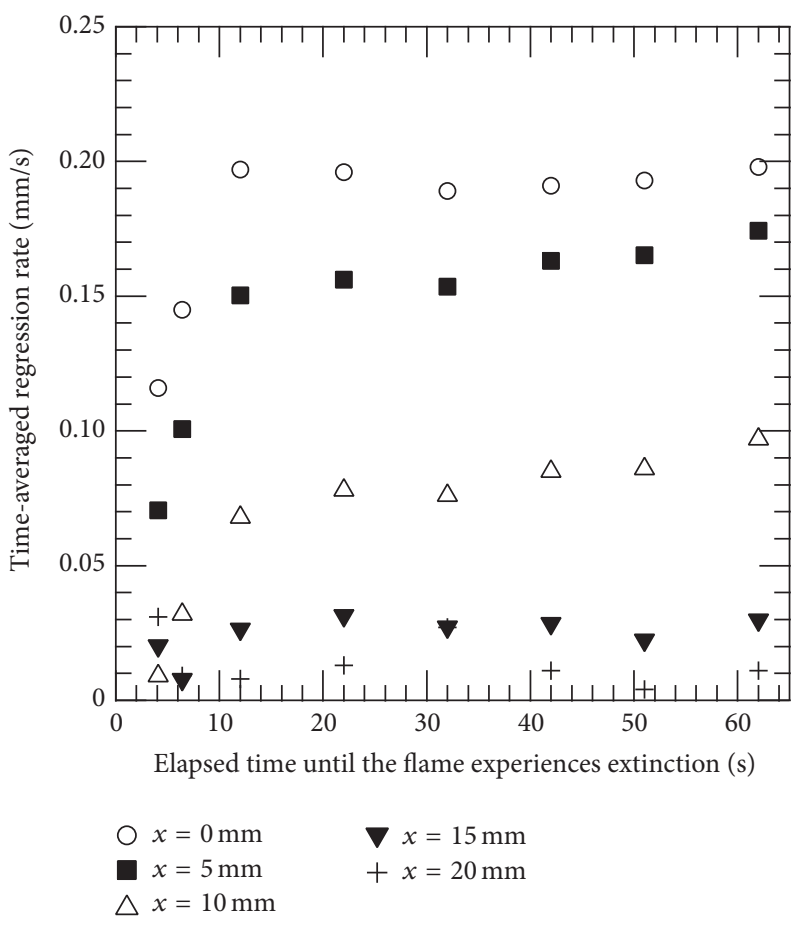

(b)

FIgURE 3: (a) The regression from the initial surface and (b) the time-averaged regression rate plotted against the elapsed time until the flame experiences extinction for $V=5.6 \mathrm{~m} / \mathrm{s}$ and $H=24 \mathrm{~mm}$.

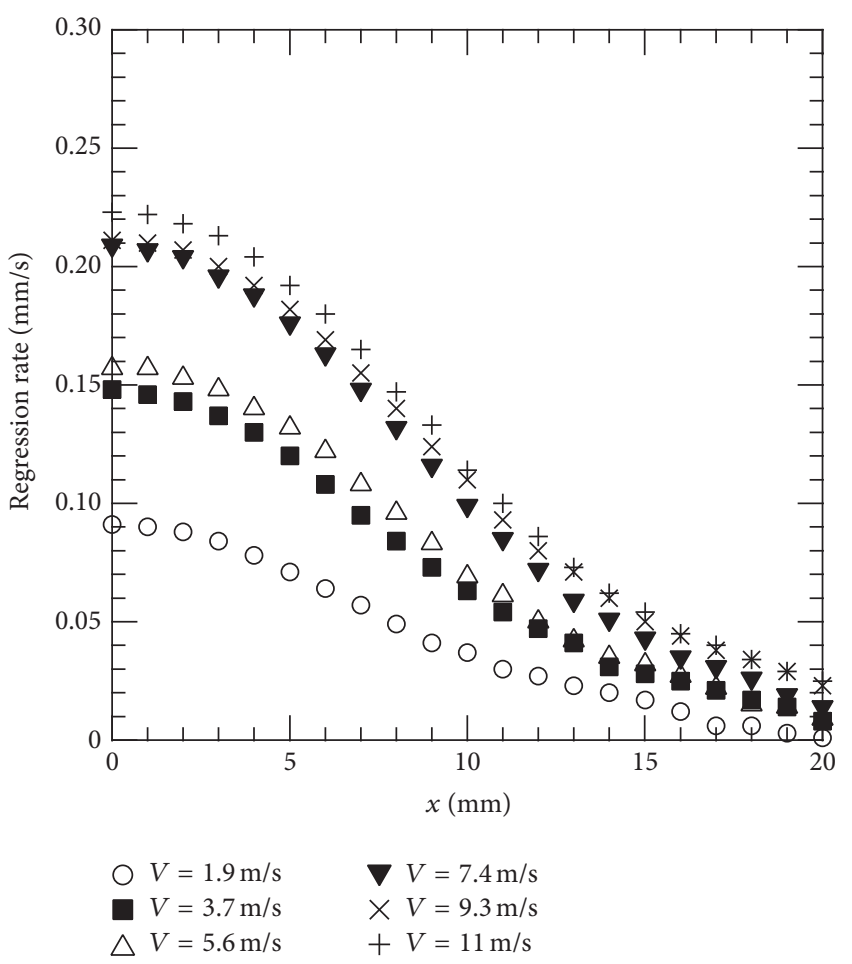

(a)

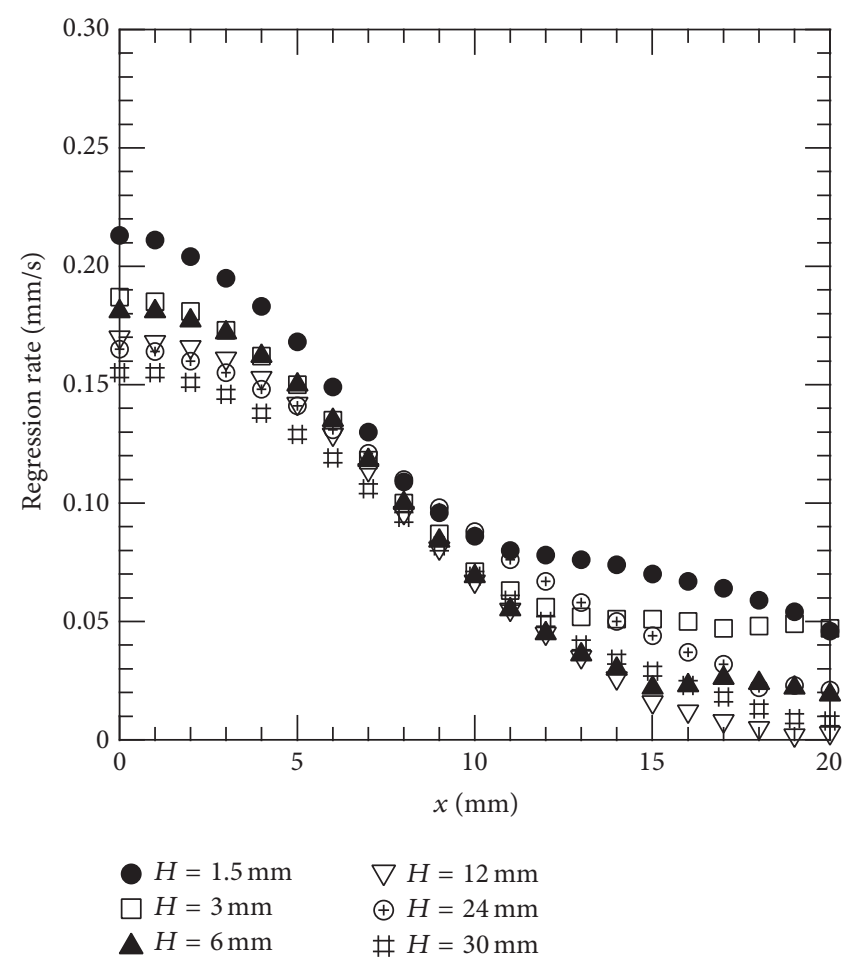

(b)

FIGURE 4: Local regression rate along the center line $(x=0)$. (a) The experiments were performed at a constant impinging distance of 24 mm and (b) at a constant impinging jet velocity of $5.6 \mathrm{~m} / \mathrm{s}$. 


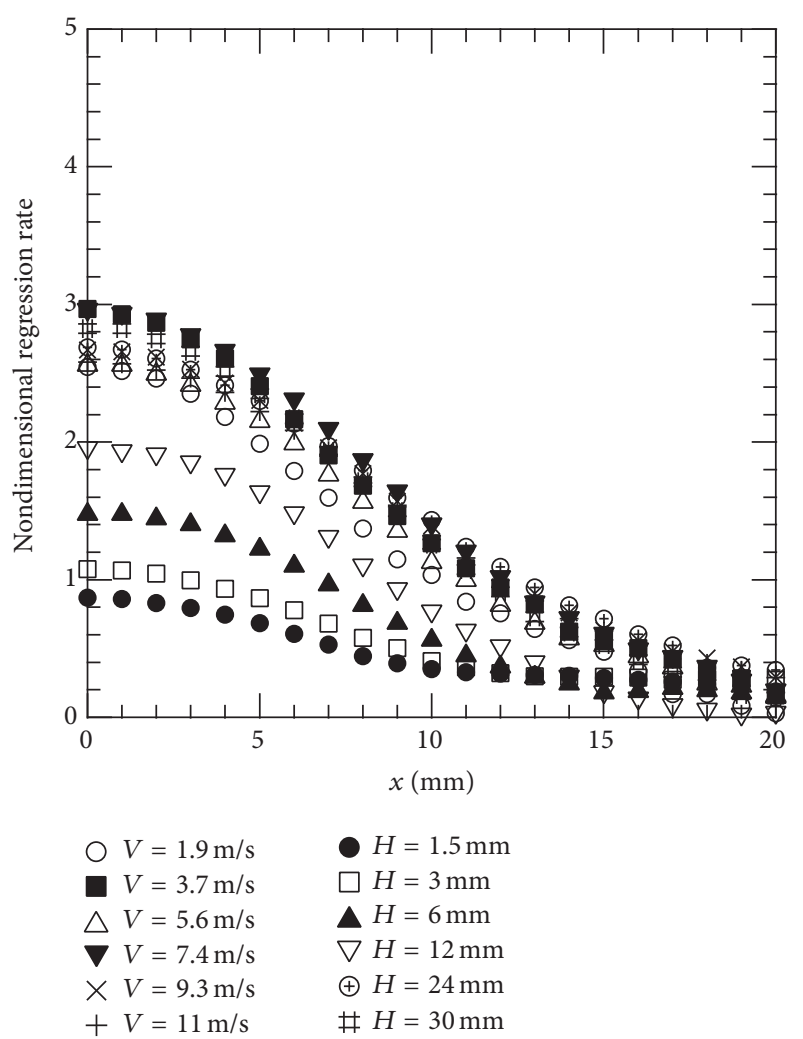

FIGURE 5: Nondimensional regression rate.

in stagnation flow, Matsui et al. [18, 19] showed that the nondimensional regression rate, defined as the regression rate divided by the characteristic velocity, is the suitable parameter to correlate the kinematic effect with the hydrodynamic effects and obtained well-summarized correlation between the Damköhler number and the nondimensional regression rate. Such nondimensional treatment is expected to work as well. Here, the characteristic velocity is expressed as $(a v)^{1 / 2}$ for the two-dimensional jet, where $a\left[\mathrm{~s}^{-1}\right]$ is the so-called stagnation velocity gradient, and $\nu\left[\mathrm{m}^{2} / \mathrm{s}\right]$ is the kinematic viscosity of the gas at the surface. The residence time is inversely proportional to the velocity gradient and the amount of momentum transfer of the evaporated fuel is evaluated by the kinematic viscosity. Hence, the velocity $(a v)^{1 / 2}$ physically characterizes the velocity of the fuel evaporated at the surface. As expected, the nondimensional regression rate, $\dot{r} / \sqrt{a \nu}$, for the various velocities and the impinging distances collapses into a single line except for $H<12 \mathrm{~mm}$ (Figure 5). This indicates that the kinetic of the gas-phase reaction needs to be taken into account due to the relatively short residence time.

The obtained regression rate shown in Figure 4 shows a similar trend to the heat transfer characteristic of a nonreactive impinging slot jet [20]. When no combustion takes place, it is known that the Nusselt number is proportional to $\mathrm{Re}^{0.5}$ in the stagnation region, while $\mathrm{Re}^{0.8}$ in the wall-jet region [21]. However, since the convective heat transfer coefficient and hence the Nusselt number depend on the flow properties such as velocity, viscosity, and other flow and temperature dependent properties, remodeling the regression behavior based on the conductive heat transfer from the flame to the solid may clarify the phenomenon and give a better regression rate formula.

3.2. Modified Regression Rate Formula for Uppermost Stage. The observation reveals that the diffusion flame covers the entire fuel surface for the condition far from the extinction limit. Ignoring the flame curvature, it is considered that the positional relation between the flame and regression surface is one-dimensional. Then, assuming the one-dimensional, quasi-steady regression motion, the heat balance equation of the control volume near the fuel surface is expressed as follows:

$$
\dot{q}_{\text {in }}=\dot{q}_{1}+\dot{q}_{2}+\dot{r} \rho_{s} L,
$$

where $\dot{q}_{\text {in }}\left[\mathrm{W} / \mathrm{m}^{2}\right]$ is the heat flux transferred from the flame to the fuel, $\dot{q}_{1}\left[\mathrm{~W} / \mathrm{m}^{2}\right]$ is the conductive heat flux through the solid, $\dot{q}_{2}\left[\mathrm{~W} / \mathrm{m}^{2}\right]$ is the radiative heat loss from the fuel, $\rho_{s}\left[\mathrm{~kg} / \mathrm{m}^{3}\right]$ is the density of the fuel, and $L[\mathrm{~J} / \mathrm{kg}]$ is the latent heat of gasification. Here, the temperature profile in the condensed phase is given by the following equation [23]:

$$
T(y)=T_{\infty}+\left(T_{s}-T_{\infty}\right) \exp \left(\frac{\dot{r}}{\alpha} y\right) .
$$

$\alpha\left[\mathrm{m}^{2} / \mathrm{s}\right]$ is the thermal diffusivity and $T_{s}[\mathrm{~K}]$ and $T_{\infty}[\mathrm{K}]$ are surface and bulk temperature of the fuel, respectively. Let $\delta[\mathrm{mm}]$ be the quenching distance between the flame and the surface, and the regression rate is expressed by the following equation:

$$
\dot{r}(x)=\frac{\left(\lambda_{g} / \delta(x)\right)\left(T_{f}-T_{s}\right)-\varepsilon_{s} \sigma\left(T_{s}^{4}-T_{\infty}^{4}\right)}{\rho_{s}\left[L+c_{s}\left(T_{s}-T_{\infty}\right)\right]},
$$

where $c_{s}[\mathrm{~J} / \mathrm{kg} \cdot \mathrm{K}]$ is the specific heat of solid, $\lambda_{g}[\mathrm{~W} / \mathrm{m} \cdot \mathrm{K}]$ is the thermal conductivity of gas phase, $T_{f}[\mathrm{~K}]$ is the flame temperature, $\varepsilon_{s}$ is the emissivity, and $\sigma\left[\mathrm{W} / \mathrm{m}^{2} \cdot \mathrm{K}^{4}\right]$ is the Stefan-Boltzmann constant.

Equation (4) shows that it is necessary to know the quenching distance for calculating the regression rate. In this study, the quenching distance was measured from the image during the combustion although it is also predictable as discussed later. Figure 6 shows front views of PMMA captured 20 seconds after ignition for $V=1.9$ and $5.6 \mathrm{~m} / \mathrm{s}$ and $H=24 \mathrm{~mm}$ with CCD camera. In order to make observation and specification of the flame easily, the glass plates of $20 \mathrm{~mm}$ height and $59 \mathrm{~mm}$ width were installed at the front and rear faces. The upper ends of both the glass plate and fuel specimen were flush against each other. In this experiment, the oxygen concentration was reduced to $50 \mathrm{vol} . \%$ to avoid thermal damage of the glass. When PMMA is exposed to the flame, surface degradation takes place due to linear pyrolysis. Figure 6 visualizes two distinctive regions: the black region corresponding to the condensed phase and the gray region where small bubbles are observed. Although the bubble layer adhered to the front and back walls inhibit clear observation from the side, it is considered that the luminous zone, which 


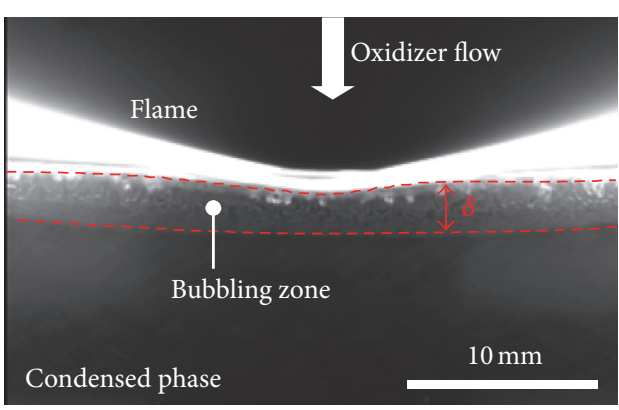

(a)

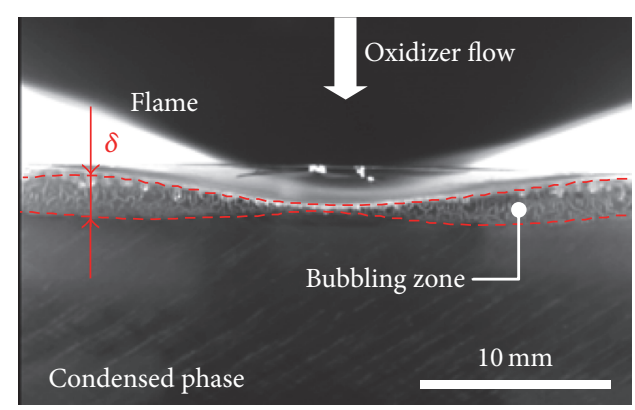

(b)

Figure 6: Photographs of PMMA burning for (a) $V=1.9 \mathrm{~m} / \mathrm{s}$ and (b) $5.6 \mathrm{~m} / \mathrm{s}$. The oxygen concentration was 50 vol.\%.

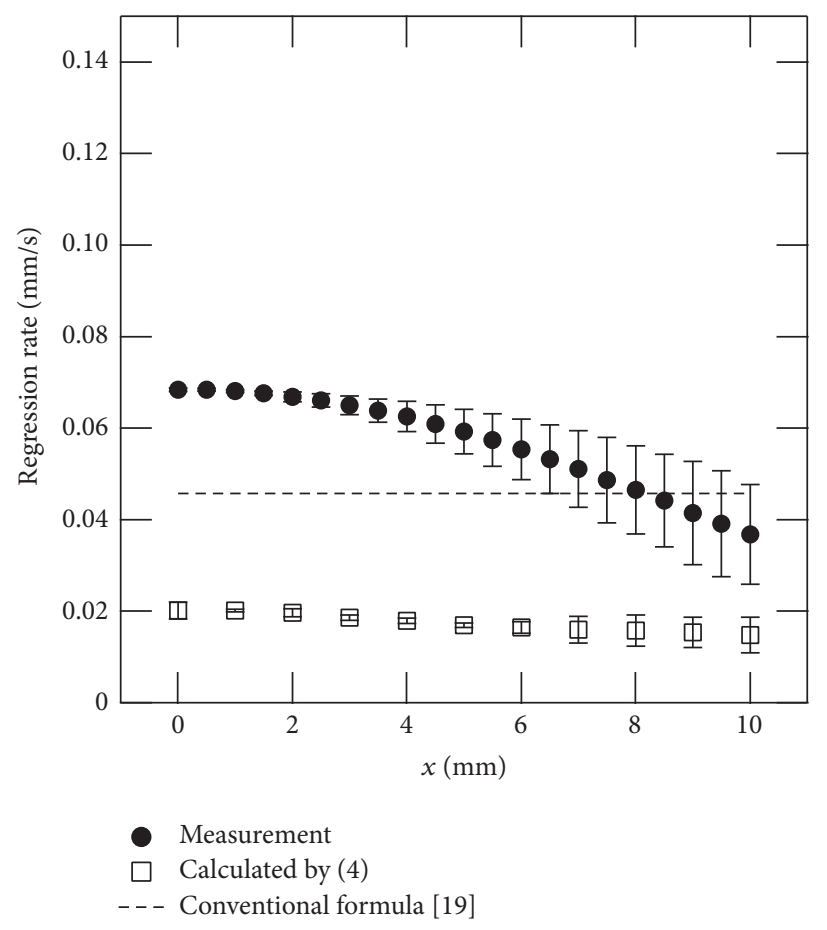

(a)

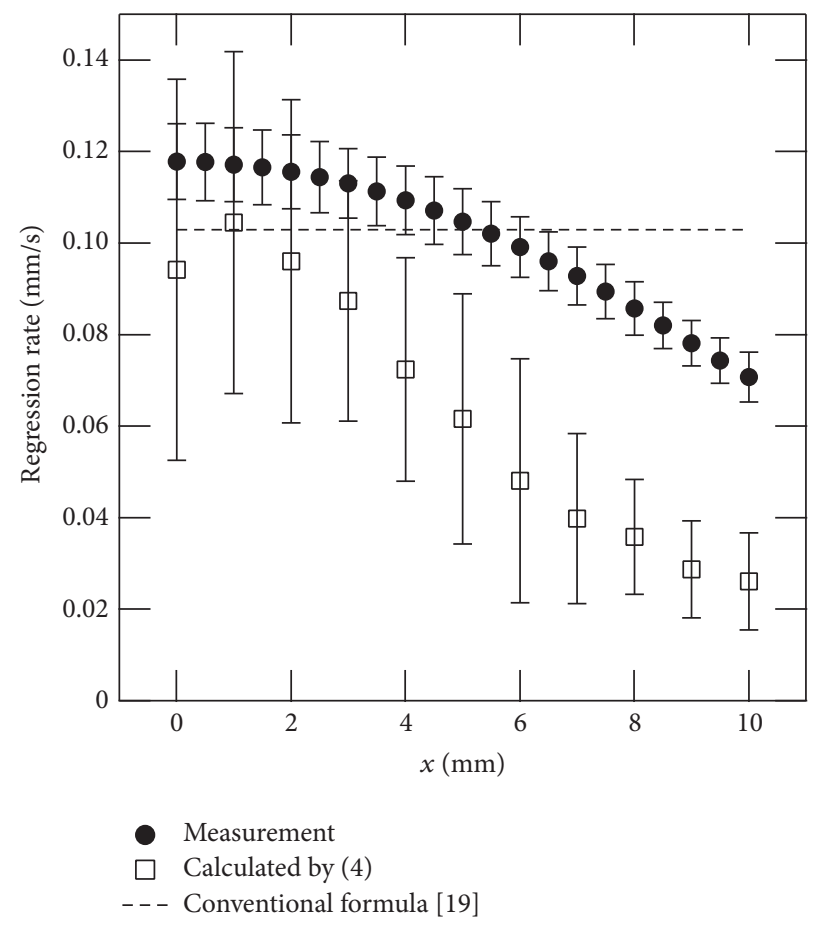

(b)

FIgURE 7: Comparison of local regression rates for (a) $V=1.9 \mathrm{~m} / \mathrm{s}$ and (b) $5.6 \mathrm{~m} / \mathrm{s}$.

appears to overlap on the boiling layer, is corresponding to the area where the luminous flame is established. The quenching distance seemed slightly changed along a wide direction for $V=1.9 \mathrm{~m} / \mathrm{s}$. Meanwhile, the flame formed closely to the surface for $V=5.6 \mathrm{~m} / \mathrm{s}$ and the quenching distance became a minimum in the vicinity of the center. Note that the visible distance between the flame and the bubbling layer (the distance between the solid and dashed line in the figure) gives the quenching distance at the central position in depth direction. Hence, in the following section, the regression rate evaluated by (4) with the measured quenching distance is that along the center line.

The regression rates were calculated by (4) and compared with the experimentally measured regression rate by the laser displacement sensor, as shown in Figure 7. Table 1 shows physical and chemical constants used in the calculation.
In order to evaluate the uncertainty, the experiments were repeated for three $(V=1.9 \mathrm{~m} / \mathrm{s})$ or four times $(V=5.6 \mathrm{~m} / \mathrm{s})$, respectively. Assuming the obtained regression rate follows the normal distribution, the uncertainty of the regression rate within 95\% confidence interval was then evaluated as 1.96 times the standard deviation of the data. The regression rate calculated by the conventional regression rate formula [17], $\dot{r}=c \operatorname{Re}^{m}(H / B)^{n}$, is also shown in the figure. The values of $c, m$, and $n$ are shown in Table 2. Although the empirical constants obtained for the CAMUI-250 motor are applied in spite of the difference of flow fields, the conventional formula reasonably agrees with the measured regression rate. However, it cannot provide the local regression rate in principle. On the other hand, the modified regression rate formula gives the local regression rate. Although the difference between the calculated and measured regression rate is relatively large, 
TABLE 1: Physical and chemical constants used for (4).

\begin{tabular}{lccc}
\hline$T_{f}$ & {$[\mathrm{~K}]$} & 2850 & Evaluated for 50 vol.\% of $\mathrm{O}_{2}$ concentration [22] \\
$T_{s}$ & {$[\mathrm{~K}]$} & 763 & p. 311 \\
$T_{\infty}$ & {$[\mathrm{K}]$} & 300 & For $1800 \mathrm{~K}$ of air $[24]$ \\
$\sigma$ & {$\left[\mathrm{W} / \mathrm{m}^{2} \cdot \mathrm{K}^{4}\right]$} & $5.67 \times 10^{-8}$ & {$[25]$} \\
$\varepsilon_{s}$ & {$[-]$} & 0.9 & {$[26]$} \\
$\lambda_{g}$ & {$[\mathrm{~W} / \mathrm{m} \cdot \mathrm{K}]$} & 0.1077 & Evaluated for $T_{s}=763 \mathrm{~K}[26]$ \\
$L_{v}$ & {$[\mathrm{~J} / \mathrm{kg}]$} & $159 \times 10^{6}$ & 1190 \\
$\rho_{s}$ & {$\left[\mathrm{~kg} / \mathrm{m}^{3}\right]$} & 2942 & \\
$c_{s}$ & {$[\mathrm{~J} / \mathrm{kg} \cdot \mathrm{K}]$} & &
\end{tabular}

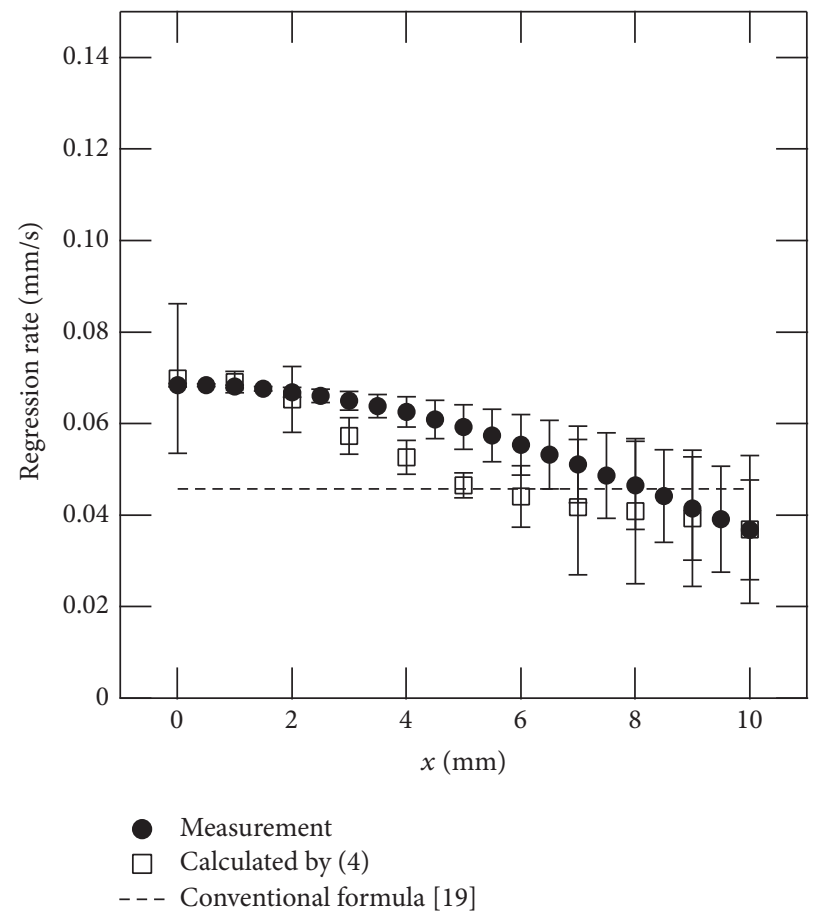

(a)

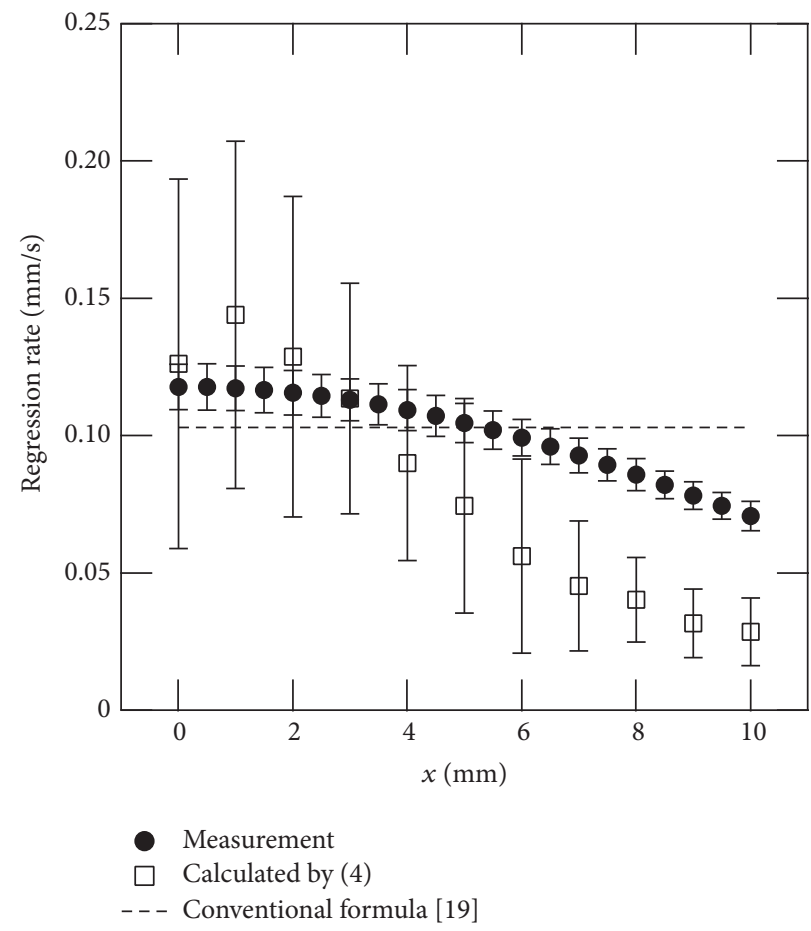

(b)

Figure 8: Comparison of local regression rates for (a) $V=1.9 \mathrm{~m} / \mathrm{s}$, offset value of $\delta=1.7 \mathrm{~mm}$, and (b) $5.6 \mathrm{~m} / \mathrm{s}$, offset value of $\delta=0.15 \mathrm{~mm}$.

TABLE 2: Empirical constants [17].

\begin{tabular}{lc}
\hline$c$ & 0.028 \\
$m$ & 0.75 \\
$n$ & -0.09 \\
\hline
\end{tabular}

especially for $V=1.9 \mathrm{~m} / \mathrm{s}$, the qualitative agreement of the trend indicates that the proposed heat balance equation reasonably predicts the regression rate once the quenching distance is identified. A possible reason to cause a large systematic error is the difficulty of accurate specification of the quenching distance. In addition, manual detection of the luminous flame edge and the interface between the bubbling zone and the condensed phase may also cause a further error. Considering the resolution of the image is about $0.05 \mathrm{~mm} /$ pixel, several tens pixels of offset greatly changes the regression rate. As shown in Figure 8, if the quenching distance is $1.7 \mathrm{~mm}$ (about 34 pixels) offset above the surface for $V=1.9 \mathrm{~m} / \mathrm{s}$, the modified regression rate formula is in good agreement with the measured regression rate, while the $0.15 \mathrm{~mm}$ offset (about 3 pixels) seems suitable for $V=5.6 \mathrm{~m} / \mathrm{s}$.

The present model is based on the energy balance between the flame and the fuel surface. Thus, the condition where the equation is applicable must be far from the extinction limit. The basic concept is applicable to the actual motor design. However, the actual CAMUI hybrid rocket motor is usually operated in much higher Reynolds number; for example, for $2500 \mathrm{~N}$ thrust class CAMUI motor, the Reynolds number ranges from about 33000 to 75000 [17]. In 
addition, the obtained regression rate formula requires onedimensional arrangement of the regression surface and the flame. When the velocity gradient is large, the flame becomes stretched and thus the regression rate formula may not be applicable.

It is expected that the obtained modified regression rate formula has a potential to predict the regression rate more precisely once the precise quenching distance is given. This is a big advantage because the flame location from the surface is predictable from the initial and ambient parameters. It is wellknown that for the droplet combustion the flame location is theoretically predicted with the Spalding mass transfer number, which represents the ratio of the driving force for vaporization of the fuel to the resistance to vaporization [27]. In turn, since the order of the regression rate is about $0.1 \mathrm{~mm} / \mathrm{s}$ for general cases performed in this study, the characteristic time for changes in the gas-phase is considered shorter than the regression behavior. Thus, the combustion phenomenon is in quasi-steady state. Therefore, once the velocity field is determined independently, the flame location is expected to be obtained by solving the governing equations in a similar manner to the droplet combustion. Further modification to predict the local regression rate without performing any experiments is expected as a future work.

\section{Conclusions}

The regression behavior of PMMA combustion with the impinging oxidizer jet was experimentally investigated and the modified regression rate formula based on a quasi-steady, one-dimensional energy balance equation was proposed. An experimental setup which simulated the uppermost stage of CAMUI hybrid rocket was developed and burning tests with 100 vol. $\%$ and 50 vol.\% oxygen were conducted. The quasisteady combustion of PMMA was successfully confirmed immediately after the ignition process. Results show that the regression rate for various flow velocities and impinging distance was well-summarized by using the characteristic velocity of evaporated fuel at the surface. For a certain condition, the obtained regression rate formula was validated by comparing the calculated regression rate with the measured regression rate, although they did not match quantitatively. It is expected that the accuracy of the calculated regression rate can be improved by precise measurement or theoretical prediction of the quenching distance. The latter way suggests a big advantage over the conventional regression formula because the present model can predict the regression rate without performing any experiments once the quenching distance is given from the condition parameters. Though this study is initiated to predict the regression rate for optimal design of the CAMUI-type hybrid rocket motor, it is believed that the basic concept is applicable to general solid combustion with impinging jet.

\section{Nomenclature}

a: Velocity gradient, $\mathrm{s}^{-1}$

$B$ : Width of slit nozzle, $\mathrm{mm}$

c: Empirical constant for (1) $c_{s}: \quad$ Specific heat of solid, $\mathrm{J} / \mathrm{kg} \cdot \mathrm{K}$

D: Port diameter, $\mathrm{mm}$

$G_{p}$ : Mass flux of propellant, $\mathrm{kg} / \mathrm{m}^{2} \cdot \mathrm{s}$

$H$ : Separation distance or impinging distance, $\mathrm{mm}$

$L: \quad$ Latent heat of gasification, $\mathrm{J} / \mathrm{kg}$

$m$ : Empirical constant for (1)

$n$ : Empirical constant for (1)

$\mathrm{Nu}$ : Nusselt number

$\dot{q}_{\text {in }}$ : Total heat flux transferred to fuel, $\mathrm{W} / \mathrm{m}^{2}$

$\dot{q}_{1}$ : Conductive heat flux through the solid phase, $\mathrm{W} / \mathrm{m}^{2}$

$\dot{q}_{2}$ : Radiative heat loss from the fuel, $\mathrm{W} / \mathrm{m}^{2}$

$r$ : Regression amount from initial grain surface, $\mathrm{mm}$

$\dot{r}$ : Regression rate, $\mathrm{mm} / \mathrm{s}$

Re: Reynolds number

$T_{f}$ : Flame temperature, $\mathrm{K}$

$T_{s}$ : Surface temperature of fuel, $\mathrm{K}$

$T_{\infty}$ : Ambient temperature, $\mathrm{K}$

$V:$ Mean flow velocity at the nozzle exit, $\mathrm{m} / \mathrm{s}$

$x$ : Horizontal axis, $\mathrm{mm}$

$y$ : Vertical axis, $\mathrm{mm}$

$\alpha$ : Thermal diffusivity, $\mathrm{m}^{2} / \mathrm{s}$

$\delta$ : Quenching distance, $\mathrm{mm}$

$\varepsilon_{s}:$ Emissivity of fuel

$\lambda_{g}$ : Thermal conductivity of gas phase, $\mathrm{W} / \mathrm{m} \cdot \mathrm{K}$

$\nu$ : Kinematic viscosity, $\mathrm{mm}^{2} / \mathrm{s}$

$\rho_{s}:$ Density of the fuel, $\mathrm{kg} / \mathrm{m}^{3}$

$\sigma$ : Stefan-Boltzmann constant: $\mathrm{W} / \mathrm{m}^{2} \cdot \mathrm{K}^{4}$.

\section{Competing Interests}

The authors declare that they have no competing interests.

\section{Acknowledgments}

This work was supported by JSPS KAKENHI Grant no. JP24860002. It was also supported by The Naito Science \& Engineering Foundation and Tatematsu-Foundation.

\section{References}

[1] M. J. Chiaverini, "Review of solid-fuel regression rate behavior in classical and nonclassical hybrid rocket motors," in Fundamentals of Hybrid Rocket Combustion and Propulsion, M. Chiaverini, K. K. Kuo, and M. J. Chiaverini, Eds., chapter 2, pp. 37-125, American Institute of Aeronautics and Astronautics, Reston, Va, USA, 2007.

[2] D. Pastrone, "Approaches to low fuel regression rate in hybrid rocket engines," International Journal of Aerospace Engineering, vol. 2012, Article ID 649753, 12 pages, 2012.

[3] S. Yuasa, K. Yamamoto, H. Hachiya, K. Kitagawa, and Y. Oowada, "Development of a small sounding hybrid rocket with a swirling-oxidizer-type engine," in Proceedings of the 37th Joint Propulsion Conference and Exhibit, AIAA 2001-3537, AIAA, Salt Lake City, Utah, USA, July 2001. 
[4] W. H. Knuth, D. J. Gramer, M. J. Chiaverini, and J. Arthur Saue, "Development and testing of a vortex-driven, highregression rate hybrid rocket engine," in Proceedings of the 34th AIAA/ASME/SAE/ASEE Joint Propulsion Conference and Exhibit, AIAA 1998-3507, Cleveland, Ohio, USA, July 1998.

[5] W. H. Knuth, M. J. Chiaverini, J. A. Sauer, and D. J. Gramer, "Solid-fuel regression rate behavior of vortex hybrid rocket engines," Journal of Propulsion and Power, vol. 18, no. 3, pp. 600609, 2002.

[6] J. R. Caravella Jr., S. D. Heister, and E. J. Wernimont, "Characterization of fuel regression in a radial flow hybrid rocket," Journal of Propulsion and Power, vol. 14, no. 1, pp. 51-56, 1998.

[7] P. G. Carrick and C. W. Larson, "Lab scale test and evaluation of cryogenic solid hybrid rocket fuels," in Proceedings of the 31st Joint Propulsion Conference and Exhibit, AIAA 1995-2948, San Diego, Calif, USA, July 1995.

[8] M. E. DeRose, K. L. Pfeil, P. G. Carrick, and C. W. Larson, "Tube burner studies of cryogenic solid combustion," in Proceedings of the 33rd Joint Propulsion Conference and Exhibit, AIAA 19973076, AIAA, Seattle, Wash, USA, July 1997.

[9] G. Risha, E. Boyer, R. Wehrman, and K. Kuo, "Performance comparison of HTPB-based solid fuels containing nano-sized energetic powder in a cylindrical hybrid rocket motor," in Proceedings of the 38th AIAA/ASME/SAE/ASEE Joint Propulsion Conference and Exhibit, AIAA 2002-3576, Indianapolis, Ind, USA, July 2002.

[10] M. Karabeyoglu, B. Cantwell, and D. Altman, "Development and testing of paraffin-based hybrid rocket fuels," in Proceedings of the 37th Joint Propulsion Conference and Exhibit, AIAA 20014503, Salt Lake City, Utah, USA, July 2001.

[11] H. Nagata, M. Ito, T. Maeda et al., "Development of CAMUI hybrid rocket to create a market for small rocket experiments," Acta Astronautica, vol. 59, no. 1-5, pp. 253-258, 2006.

[12] L. Uematsu Electric, 15kN Thrust Class CAMUI-Type Hybrid Rocket Motor Static Firing Test, 2014, https://www.youtube.com/ watch? $\mathrm{v}=\mathrm{jMSsNrPiLA0.}$

[13] G. Marxman and M. Gilbert, "Turbulent boundary layer combustion in the hybrid rocket," Proceedings of the Combustion Institute, vol. 9, no. 1, pp. 371-383, 1963.

[14] G. A. Marxman, "Combustion in the turbulent boundary layer on a vaporizing surface," Proceedings of the Combustion Institute, vol. 10, no. 1, pp. 1337-1349, 1965.

[15] Y. Kaneko, M. Itoh, A. Kakikura et al., "Fuel regression rate behavior of CAMUI hybrid rocket," Transactions of the Japan Society for Aeronautical and Space Sciences, Space Technology Japan, vol. 7, no. ists26, pp. 77-80, 2009.

[16] H. Nagata, S. Hagiwara, Y. Kaneko, M. Wakita, and T. Totani, "Development of regression rate formulas for CAMUI type," in Proceedings of the 46th AIAA/ASME/SAE/ASEE Joint Propulsion Conference and Exhibit, AIAA 2010-7117, Nashville, Tenn, USA, July 2010.

[17] H. Nagata, S. Hagiwara, N. Wakita, and T. Totani, "Optimal fuel grain design method for CAMUI type hybrid rocket," in Proceedings of the 47th AIAA/ASME/SAE/ASEE Joint Propulsion Conference and Exhibit, AIAA 2011-6105, San Diego, Calif, USA, July 2011.

[18] K. Matsui, A. Kôyama, and K. Uehara, "Fluid-mechanical effects on the combustion rate of solid carbon," Combustion and Flame, vol. 25, pp. 57-66, 1975.

[19] H. Tsuji and K. Matsui, "An aerothermochemical analysis of combustion of carbon in the stagnation flow," Combustion and Flame, vol. 26, pp. 283-297, 1976.
[20] M. Zukowski, "Heat transfer performance of a confined single slot jet of air impinging on a flat surface," International Journal of Heat and Mass Transfer, vol. 57, no. 2, pp. 484-490, 2013.

[21] M. Kumada, T. Nakatogawa, and K. Hirata, "Heat and mass transfer by Impining Jet," Journal of Japan Society of Mechanical Engineering, vol. 76, no. 655, pp. 822-830, 1973 (Japanese).

[22] S. Bhattacharjee, "The Expert System for Thermodynamics," http://www.thermofluids.net.

[23] N. A. Khalturinskii and A. A. Berlin, "High-temperature pyrolysis of thermoplastic polymers," in Degradation and Stabilization of Polymers: A Series of Comprehensive Reviews, H. H. G. Jellinek, Ed., vol. 1, chapter 6, pp. 289-336, Elsevier Science Publishers B.V., Amsterdam, The Netherlands, 1983.

[24] K. Kadoya, N. Matsunaga, and A. Nagashima, "Viscosity and thermal conductivity of dry air in the gaseous phase," Journal of Physical and Chemical Reference Data, vol. 14, no. 4, pp. 947970, 1985.

[25] N. Hashimoto, H. Nagata, T. Totani, and I. Kudo, "Determining factor for the blowoff limit of a flame spreading in an opposed turbulent flow, in a narrow solid-fuel duct," Combustion and Flame, vol. 147, no. 3, pp. 222-232, 2006.

[26] Y. Nakamura and T. Kashiwagi, "Effects of sample orientation on nonpiloted ignition of thin poly(methyl methacrylate) sheet by a laser: 1 . Theoretical prediction," Combustion and Flame, vol. 141, no. 1-2, pp. 149-169, 2005.

[27] J. C. Yang, "Heterogeneous combustion," in Environmental Implications of Combustion Processes, I. K. Puri, Ed., chapter 4, pp. 97-107, CRC Press, Boca Raton, Fla, USA, 1993. 


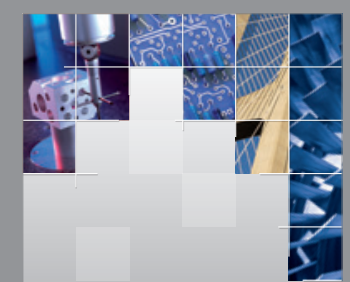

\section{Enfincering}
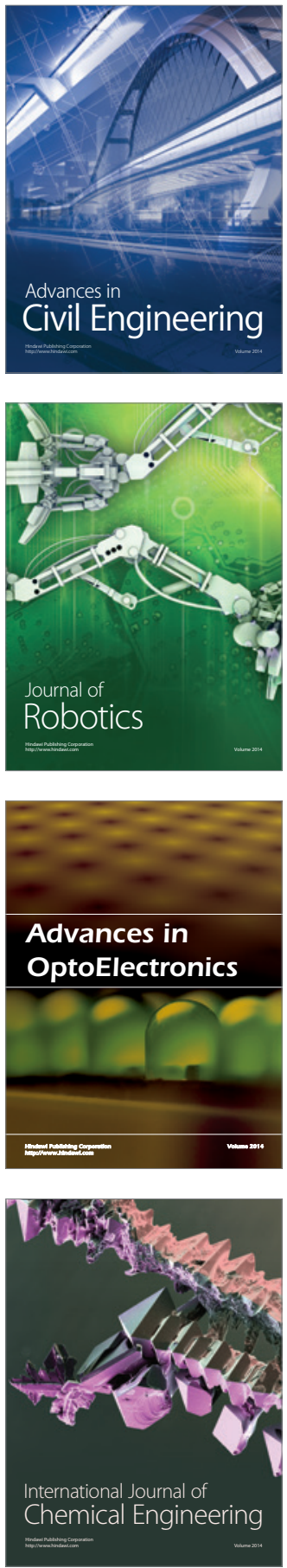

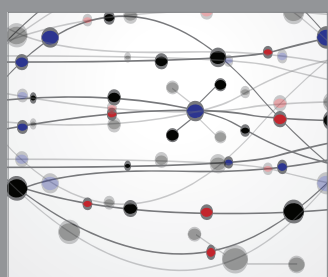

The Scientific World Journal

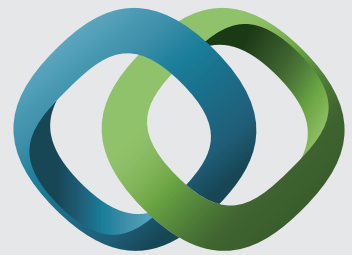

\section{Hindawi}

Submit your manuscripts at

https://www.hindawi.com
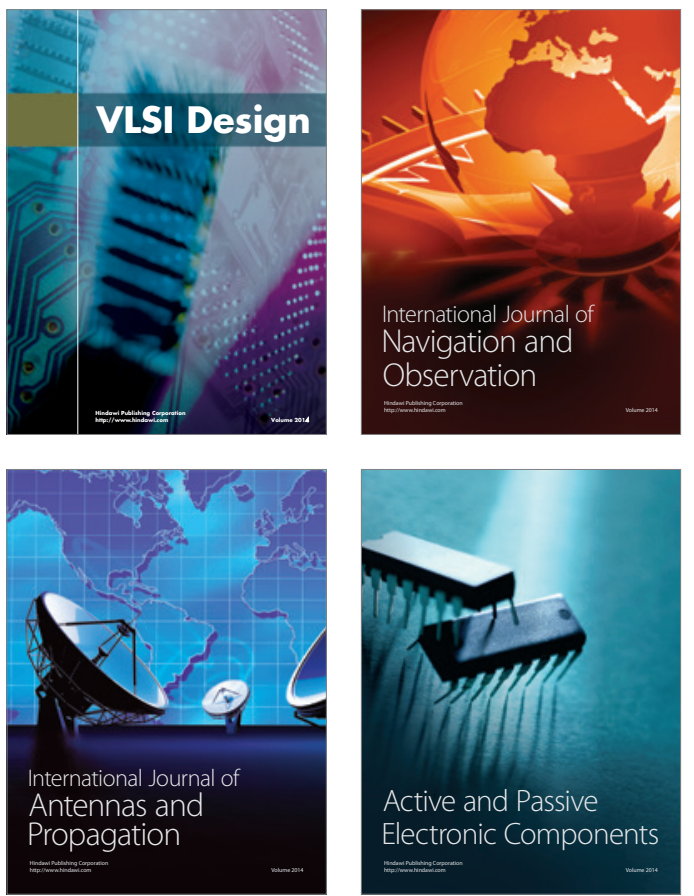
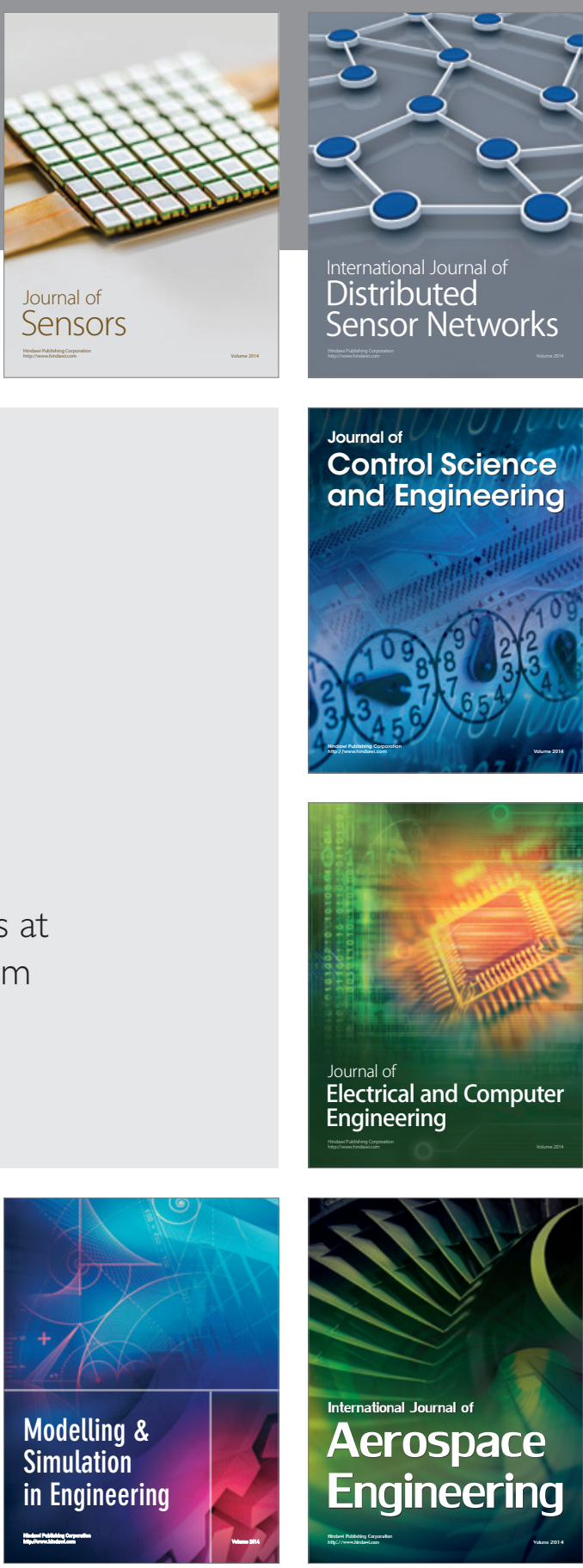

International Journal of

Distributed

Sensor Networks

$-$

Joumal of

Control Science

and Engineering
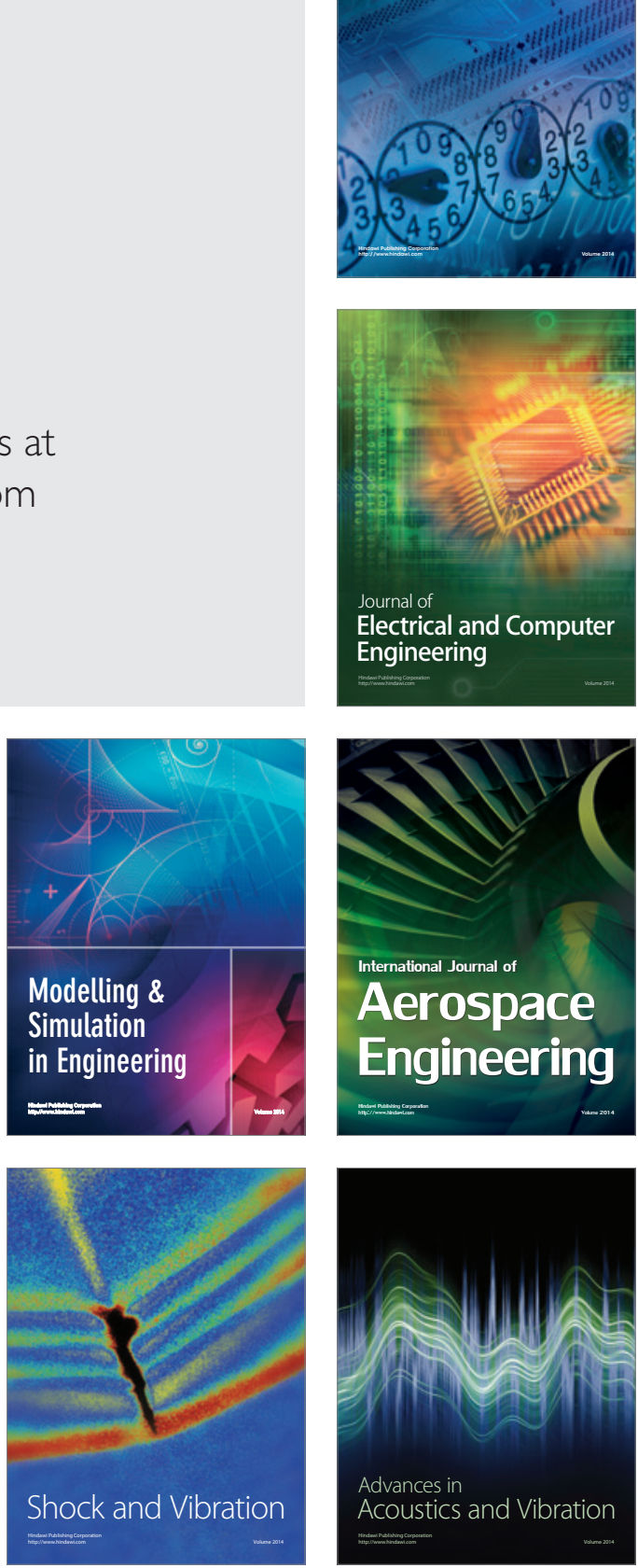